\title{
Strategy Discussion of Chinese Auto Industry via Innovative Theory of Source
}

\author{
Jianfeng $\mathrm{Ke}^{\mathrm{a}}$ and Zhaofeng Diao ${ }^{\text {,** }}$ \\ School of Management of Wuhan University of Technology \\ akejianfeng@whut.edu.cn, ${ }^{b}$ diaozf@163.com
}

\begin{abstract}
Based on the Innovation Theory of Source(ITS), the main contents are two sides market models and platform strategy, combined with the current development of the traditional auto industry, the author first leads to the basic theory of ITS, and then combined with a ITS theory analysis of the current development of the automobile industry four issues facing the automotive industry by establishing the last major new ideas, build the automotive industry on both sides of the market model, to build Chinese auto industry ecosystem gradually explore these three parts to Chinese auto industry development strategy based on ITS theory.
\end{abstract}

Keywords: Automobile, Source Innovation, Strategy Innovation

\section{Introduction}

At Stanford University Professor Edison Tse points out the significance of Innovation refers to the meaning of a new value, rather than a new technology, new product or new service. Because new products or new technologies who have no business value can't bring profit, but a waste of resources. Not only the new technology or new product but also the new desire of consumer can trigger the Innovation Theory of Source (ITS). After sixty years' development, Chinese auto industry experienced three periods of development wave. "The first wave" - the initial formation of Chinese auto industry, "the second wave" - the hard development period of Chinese auto industry, "the third wave" - the accelerated development of Chinese auto industry, it has formed an annual scale sales of over 20 million. Whether it is automotive technology, automotive business size or extent of sub-sectors, Chinese auto industry has made great progress. But if only consider vehicle sales, the number of patents, it does not mark the overall level of Chinese auto industry is in rapid development, the key lies in whether there are constantly new markets are opened, there is a new generation of value. If fix develop any market, or any one of the value chain, the market or value chain will be moving into a jog and stagnation [1-5].

\section{Introduction of ITS}

\subsection{The Relation Among Original Innovation, Chain Innovation and Source Innovation}

At Stanford University Professor Edison Tse puts forward innovation is divided into two categories, one is scientific innovation, and the other is the business innovation. Its hierarchy relationship shows as Figure 1.

* Corresponding Author 


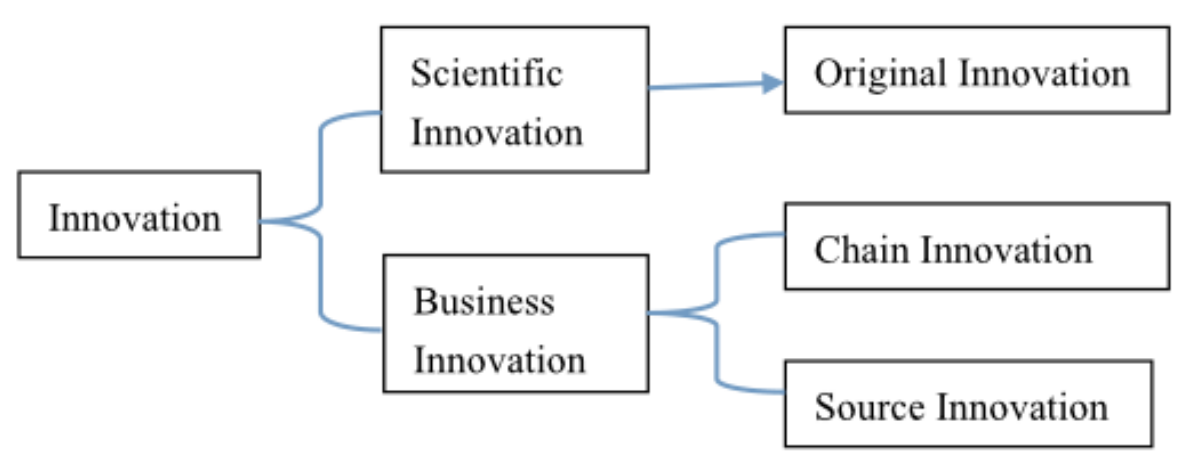

Figure 1. Relationship Between Innovations

Professor Edison Tse theorizes scientific innovation as the original innovation, referring to new discoveries about the laws of nature, including scientific theories, new products and new technology. We often mention the "independent innovation" means innovation for the origin. Considering original innovation, it has no value without business, its value lies in how we use it. For businesses, the key is not who is the creator but whether the enterprise has the ability to apply original innovation to create value.

The process of applying innovation to create value is business innovation, business innovation includes two categories, one is the Chain Innovation, the other is the Source Innovation.

The Chain Innovation is the activities to improve the existing value chain, it is to use original innovation to improve existing products, to identify complementary products, reduce costs and accelerate the development of new products, recycling optimization process, and gradually establish a process management culture, this is an innovation, but also a management method. Chinese has an old saying 'Create the Source and Reduce the Outflow'. The chain of the so-called 'Chain Innovation' is this flow of this old Chinese saying. Chain Innovation means to maximize value creation by optimizing their own resources. Only reduce the outflow but not create the source, the 'Reduce the outflow' will gradually enable enterprises to into a crisis. Through this management approach, companies can effectively control costs, production goals, avoid mistakes employees work in process, and can immediately produce benefits, but this management method of 'Reduce the outflow' will result in the reduction of profit or stagnation, enterprise competition in the industry and allowing companies to gradually fall into a difficult situation [6-8].

Another business innovation is the Source Innovation which is the so-called 'Create the Source', the so-called innovation is the adoption of new ideas, a combination of existing resources (all relevant internal and external resources) to create new value process of desire. In Western circles, there is a relatively concept who is close to the meaning of Source Innovation, that is Disruptive Innovation which means such innovations would undermine existing market's generate new values, but mainly refers to new technologies devastating. The Source Innovation means that new ideas are not necessarily driven by the new technology, it may be based on a new desire, new ideas, new values demand. And when a new idea was born, we often do not see the value or the interest, it is because there is not a value system to match with the new concept (Professor Edison Tse called it ecosystems), such as car birth, its concept is 'car is a convenient means of transport', when roads, gas stations, and so when the supply chain is not established, the car can only be a new product, an product by original innovation, most a few rich people used to show status of exhibits. But when the car's value chain, the road value chain, the gasoline value chain, the vehicle maintenance services value chain and auto finance value 
chain, and so on car-related value chain (which are streams innovation) are set up, the new concept 'car exists as a convenient means of transport' will achieve a source innovation, so the source innovation is through the creation of a new ecosystem, so that the value of new ideas generated and continue to increase, the combination of all relevant resources to the innovation process. Therefore, the source of innovation is the core dynamic competitive strategy, from a management point of view, the source of innovative ideas and strategic thinking Porter's competitive strategy is the opposite [9-10].

\subsection{Connotations of ITS Strategy}

Target of source innovation strategy is the establishment of a new concept around the ecosystem, the most fundamental difference between the source and chain of innovation. The source of innovation focus on new markets, the key is not the product, but how to help people achieve the desire. Source innovation aimed at achieving a new concept, and the source of innovation is actually the integration of external resources using their own resources, and to create a new eco-system to achieve long-term process of development and transformation. Core of source innovation is the built of model on both sides of the market, through its own innovative strengths to stimulate the flow of positive network effects on both sides of the market, the root of both sides of the competitive market model is to understand the customer's desire and ability of both sides, the combination of their own resources and customer side and the ability to satisfy the desire of the other side. Typically, in an eco-system which includes a plurality of sides of the market, but also has links between the market and the market in which the ecosystem, a market of one side or the whole market can often be used as a fulcrum to support the market to another within the system.

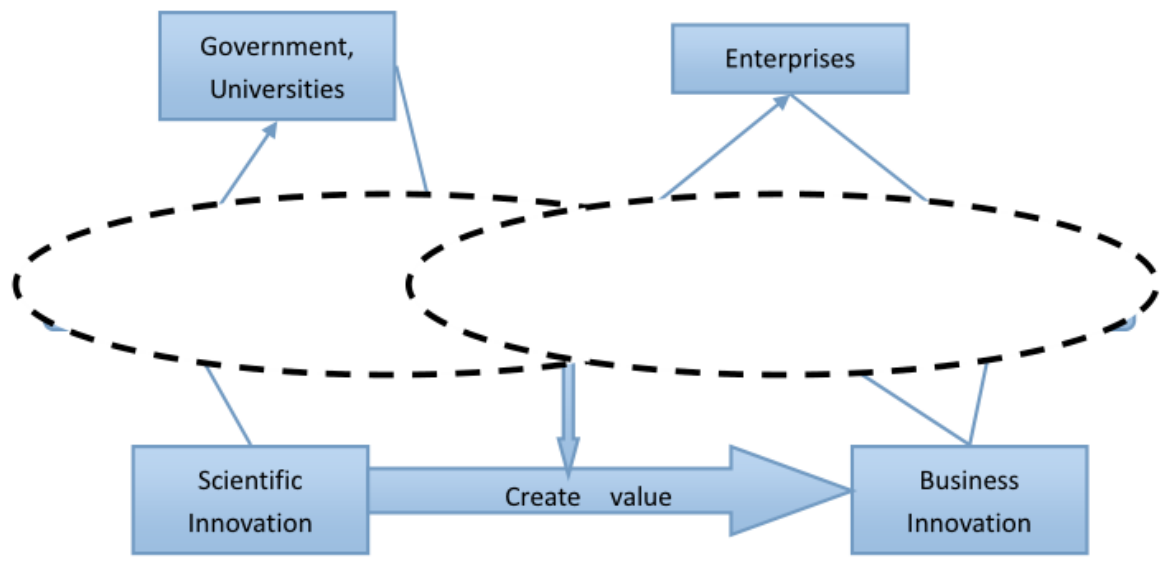

Figure 2. Source of Innovation Theory

\section{Status Quo of Chinese Auto Industry}

China's auto industry is big but not strong enough, the development of its independent brands is also very slow. According to the data of 2011 to 2014 in the car sales, the brands in the top ten include no independent ones. From a macro point of view, China's independent brand development route has no essential difference form foreign brands', also take the product as the core, and strengthen all links of the value chain, upgrade the technology, expand the scale, improve production efficiency and in other ways of flow innovation. These practices may be effective in short term, but they both belong to the homogeneous competition and homogeneous 
and development. Therefore, China's auto enterprises (independent brands, joint venture brands, foreign brands in Chinese market) can easily enter a stage of stagnant development. As independent brands, they still take the old road in the new era, completely in a set of flow innovation strategy. The pattern in the nation is that the development of independent brands is significantly slower than the joint ventures brands and foreign brands (and joint venture brands and foreign brands in China's development has entered a price war situation).In China, the vast majority of Chinese auto companies are in the transition bottleneck period, but there are not so many enterprise taking source innovation as the development strategy, the majority are developing based on flow innovation, such as the case of Geely's acquisition of Volvo's. Geely and Volvo's integration, from the current point of view, Geely's purpose is to use Volvo's brand influence and technical strength, along with its own advantages to improve Volvo's sales in China, In the first two years after the acquisition, Geely Volvo's sales was really promoted. However, since the beginning of the third year, its sales have dropped to the previous level before the acquisition, which is due to the reasons of taking the road of flow the innovation. Summing up the problems arise in the development of China's auto industry, there are four points we need to notice: the development of the automotive market is not perfect, technology and strong independent brands are lacked, the entire vehicle business scale is small and the relationship between vehicle business and parts does not conform to the trend of the world.

\subsection{Unsound Development of Automotive After-Market}

In the global production network, each link of the automobile industry is interdependent and restricted with one another. Marketing, customer service, etc are in the right side of the smile curve, with a high added value. Developed countries auto marketing usually applies the way of combining the brand franchise stores featuring in sales, maintenance and decoration together with auto trade market featuring specialty accessories. The car franchise stores can sell all kinds of brands, in fact, it is the sales agency for car brands, which is similar to the platform strategy of source innovation, but it is still not a platform strategy. They also actively create their own global marketing network, establishing their own finance companies, to provide customers with comprehensive financial services. China's vehicle enterprises have a lot of disadvantages in competing with the international competitors in these aspects, like the car sales system is not perfect, after-sales service is poor, the degree of specialization is low, automotive financial services develop slow, etc.But even these aftermarket all get developed, the result is still that they enter the situation of a homogeneous competition, because they are all based on the same value chain development strategy. They have a similar even the same concept and vision.

\subsection{Lack of Core Technology and Powerless of Own Brand}

China uses the "market replaces technology" strategy, but the core technology is still controlled in the multi-national corporation. Because of the pursuit of shortterm profit growth, the joint venture enterprises have little investment in research and development, causing our country's auto industry to fall into a vicious cycle of technological backwardness $\rightarrow$ imitation of the introduction $\rightarrow$ backward technology $\rightarrow$ imitation of the after-introduction. Also due to the lack of core technology in the R \& D of automotive industry, product development ability is weak, and it is hard to go on with the road of independent brands. Although some of the independent brand products in some segments of the market or local areas of the market have achieved a certain market dominance, but overall, compared with the 
joint venture brand, it is still lack of competitiveness. The "market for technology" strategy goes against the point of "open up new markets" in the source innovation theory.

\subsection{Inadequate Business Scale Vehicle Enterprises}

Business scale has a very important significance for the international influence of the whole vehicle enterprise. China industry insight network research department statistics show that according to 2013 the world's top 500 list of vehicle sales data, the average sales of foreign vehicle companies is about 413 , while the average sales of Chinese automobile enterprises is only about 221. Except Shanghai automotive industry corporation sales volume exceeds the average level of the world and foreign vehicle companies, China's vehicle sales volume has a large gap to the global average level. The total sales of Zhejiang Geely Holding and Guangzhou Automobile Group, are 91.34 and 71.22 respectively. In addition, seen from the operating income and asset size, Chinese vehicle enterprises are also weaker than foreign vehicle companies. In terms of platform strategy, the phenomenon of the winner taking all will usually appear in the enterprises which successfully implemented the platform strategy. These enterprises' scale are usually very large.

\subsection{Imbalance Between Parts Enterprises and Vehicle Enterprises}

The relationship between developed countries vehicle business and parts enterprises mainly has two modes, namely the pyramid of vertical division of labor system represented by Japan between the vehicle business \& parts enterprises and the development model of competing and cooperating with each other but mutually independent represented by Europe. The situation of United States is similar to Europe's, but the responsibility between vehicle business and parts enterprises the more clear. At present, these two models have obvious trend of mutual learning and mutual integration. China's relationship between vehicle business and parts enterprises is more complicated, but mainly can be divided into two categories: one is attached to the parts enterprises of vehicle business, the other is attached to an independent parts suppliers. China auto market is mainly based on parts enterprises of the first category. This relationship often makes the vehicle enterprises in the core position, and the parts enterprises lack awareness of competition, which is not conducive to the development of new products and saving management costs. In two-sided markets, there is no absolute upstream-downstream relationship between enterprises and enterprises, and between enterprises and customers, the two sides of the market shares the equal and harmonious relationship.

\section{New Value Concept Construction of Automotive Industry}

The first step in taking source innovation theory as the strategy is to put forward a new idea of value.

\subsection{The Traditional Values of Auto Industry-Transportation with a Status Symbol}

In China, the traditional value concept of taking a car is "the car is not only a convenient means of transport, but also a property symbolizing ability and status (hereinafter referred to as the "transport and property concept"), and therefore the mainstream value chain of China's automotive industry is taking the vehicle factory as the core, and the vehicle sales and maintenance as the main source of value, with the small scaled car rental, car maintenance, car finance, car modification and auto recycling and other non-mainstream automotive industries. Therefore, even China such a big market, will also face the quick saturated state of auto industry in the 
near future. In the second half of 2014 and the first half of 2015, many 4S shops are forced to cut prices because they couldn't meet the required car factory sales volume, and even some $4 \mathrm{~S}$ shop began to withdraw from the network, which all marks the traditional car factory-4S special distribution model has been close to the stagnation. Therefore, to break this situation, we must first establish a new value concept.

\subsection{New Auto Industry Concept-Around Demand Instead of Product}

If the concept of the Chinese auto industry in the future is still to fully take the product as the center, with technological advances and other innovative flow as a strategic orientation, Chinese auto enterprises will be difficult to break through the bottleneck and many companies will be difficult to survive. Combining China's own culture, the development level of world's automotive industry and the Internet, we can easily establish the following ideas: standing on personal point of view: "Let everyone can ride and use the right car at low cost ", "make the private car no longer a loss, private cars can also add value"; standing on the nation's point of view: "make full use of all the vehicle resources to build a recycling car society". These concepts can make the car no longer a private property of minority people as a symbol to distinguish the status; private cars are also not entirely consumables and private cars are no longer in a state that the seats cannot be fully taken; cars are also able to be recycled.

\section{Building the both Sides of the Market Model for the Automotive Industry}

According to the concepts above, based on the theory of source innovation, the second step is to establish two-sided models---various models work together can form an ecosystem.

"Let everyone can ride and use the right car at low cost", in this concept, you can set up a car service platform, the left side of the vehicle factory and the owner, the right is the persons who want to use their favorite car in any time at low cost, they can choose order the new car in the vehicle factory, and also can choose a suitable private car; and then owners, vehicle factory and personal can communicate directly. The platform is only responsible for management and does not participate in any specific transaction.

"Make full use of all the resources of the car, to establish a cycle automobile society". Under this concept, vehicle factories, universities scientific research institutions and car recycling business can form a cycle of value chain among each other. Vehicle factories use the universities and research institutions technology to refurbish the sub-new cars, and put them back into the market; and put the scrapped car to the vehicle recovery and remanufacturing enterprises, the vehicle recycling enterprises use universities scientific research technology to retreat the usable auto parts; and then the retreated parts will be output to the vehicle factories and various parts suppliers, etc.

Through the establishment of two-sided market model, China's auto industry will no longer take the whole vehicle factory as the sole core and other automobile related enterprises perform as the supporting role, but will develop a situation that the vehicle factory, car rental companies, automobile recycling and remanufacturing enterprise, university research institutions, car modification, car repair \& maintenance \&beauty enterprises and auto finance companies develop fairly and harmoniously.

The two-sided market itself is to use the platform's own resources to combine into one-sided resources to meet the needs of the other side, and the other side 
resources can play a supporting role in another market, so that all the two-sided modes in the automotive industry can have a mutual connection.

\section{The Establishment of the Automotive Industry Ecosystem}

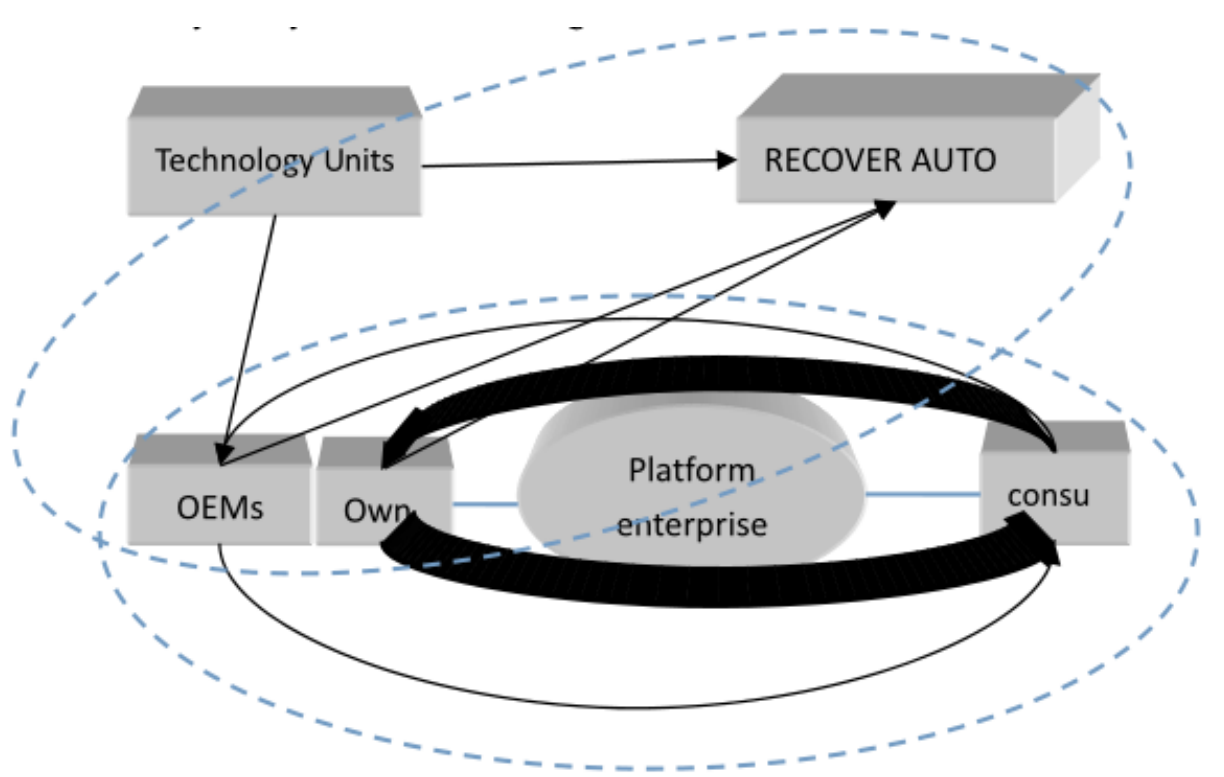

Figure 3. Automotive Industry Ecosystem Shows

In the core of the second step, after the two sides to achieve the establishment of the market model, the automotive industry has been established with the foundation of ecosystems, the key lies in establishing an innovative ecosystem to continue to strengthen links between the platform, so that any car-related companies can use their own resources to enter new markets on both sides. For example: the use of Chinese current electricity supplier platform for enterprise resource capacity, integration of the global automobile companies (almost all international brands have production bases in China), car rental companies and local private owners, then led by the government, the university research institutions, automobile recycling companies and OEMs together to form a number of new car market. Automotive industry ecosystem shows in Figure 3.

\section{Conclusion}

Chinese automobile industry is facing the gradual stagnation situation, it need to inject new development strategy, and the chain innovation strategy is not consistent with the current trend of China Intelligent Information Age. In this gradually symmetrical information age, Chinese auto industry needs the source innovation as a development strategy. Chinese automobile market value redefines with the ITS theory. The platform on both sides of the market inspires the automobile industry, The interaction among 'the Innovation of Source', 'the Original Innovation' and "Innovation of chain" trigger a series of innovative activities to promote the healthy development of Chinese automobile industry. The interaction also promote the adoption of new core concept the formation of the automobile industry innovation ecosystem, and to interact with other related industries to format a recycling economy. 
International Journal of $u-$ and e- Service, Science and Technology

Vol.9, No. 5 (2016)

\section{References}

[1] M. E. Porter, "Competitive Strategy: Techniques for Analyzing Industries and Competitors", Free Press, New York, (1980).

[2] G. Hamel and B. Breen, "The Future of Management", Harvard Business School Press, (2007).

[3] H. Mintzberg, B. Ahlstrand and J. Lampel, "Strategy Safari: A Guide Tour Through the Wilds of Strategic Management”, Free Press, New York, (1998).

[4] C. Anderson, "The Long Tail: Why the Future of Business is Selling Less of More", Press Corporation, (2007).

[5] A. Botthof and E. A. Hartmann, "Zukunft der Arbeit in Industrie 4.0", Springer Science +Business Media, (2015).

[6] L. Bainbridge, "Ironies of automation”, Automatica, vol. 19, no. 6, (1983), pp. 775-779.

[7] R. Parasuraman and D. H. Manzey, "Complacency and bias in human use of automation: an attentional integration", Journal of the Human Factor and Ergonomics Society, vol. 52, (2010), pp. 381-410.

[8] Y. Yamauchi, "Participatory design", In T. Ishida (Hrsg.), Field informatics, Springer, (2012), pp.123-138.

[9] C. M. Burns and J. R. Hajdukiewicz, "Ecological interface design", Boca Ration CRC Press, (2004).

[10] C. Forsythe, M. L. Bernard and T. E. Goldsmith, "Human cognitive models in systems design", Mahwah: Lawrence Erlbaum Associate, (2005). 